\title{
PROJETO PARTICIPATIVO DE SINALIZAÇÃO ACESSÍVEL PARA A REITORIA DA UFPB
}

VI SBQP

\author{
NÓBREGA, Abraão Pinto de Oliveira \\ Universidade Federal da Paraíba, e-mail: abraaonobrega02@gmail.com \\ VIEIRA, Maria Carolina dos Santos \\ Universidade Federal da Paraíba, e-mail: caroolinavieir@gmail.com \\ DINIZ, Marcelo Andrade \\ Universidade Federal da Paraíba, e-mail: marceloadiniz@gmail.com
}

\begin{abstract}
RESUMO
Este projeto surgiu através de uma pesquisa de extensão - PROEXT 2018 - por meio de um anteprojeto de sistemas de sinalização acessível, foram geradas um conjunto de propostas a serem implantados no primeiro pavimento da reitoria da Universidade Federal da Paraíba - UFPB. A pesquisa teve sua etapa de diagnóstico e diretrizes projetuais finalizada em dezembro de 2018, seguindo para a continuação e detalhamento executivo em 2019. Sua realização se mostrou necessária pelo grau de dificuldade da legibilidade espacial da edificação situada no Campus I, João Pessoa, Paraíba. Dado seu programa de necessidades de alta complexidade foi necessário o recorte de estudo em apenas um pavimento, possibilitando o aprofundamento do diagnóstico e reconhecimento da edificação. Seu objetivo principal foi entender as demandas dos usuários com e sem deficiência para então propor soluções baseadas no desenho universal e nas normativas de acessibilidade, como a NBR 9050 (ABNT, 2015) e Lei $n^{\circ} 13.146$ (BRASIL, 2015). A etapa de diagnóstico se desenvolveu através de visitações, passeios acompanhados e questionários semiestruturados. Após a revisão bibliográfica e reconhecimento do objeto empírico houve a etapa projetual com ênfase na participação da comunidade através de workshops. O resultado parcial do primeiro ano foi a prototipagem de 144 placas em escala real e de um dos mapas táteis propostos, a paginação de pisos táteis, além das diretrizes de organização dos sistemas para o aprofundamento e continuidade do projeto que viria para embasar o direito de ir e vir da comunidade igualitariamente.
\end{abstract}

Palavras-chave: Reitoria da UFPB, Sinalização Acessível, Prototipagem, Projeto Participativo.

\begin{abstract}
This project came about through an extension research - PROEXT 2018 - by means of a design of accessible signaling systems, for be implemented on the rectory's first floor of the of the Federal University of Paraíba (UFPB) was created through a project of accessible signaling systems. The research had its diagnostic stage and project guidelines finalized in December 2018, followed for the continuation and executive detailing in 2019. Its accomplishment was necessary for the degree of difficulty of the space's legibility of the building located in Campus I, João Pessoa, Paraíba. Given its highly complex needs program, it was necessary to clipping the study in only one floor, allowing the deepening of the diagnosis and recognition of the building. Its main objective was to understand the demands of disabled and non-disabled users to propose solutions based on universal design and accessibility normatives, such as NBR 9050 (ABNT, 2015) and Law 13,146 (BRAZIL, 2015). The diagnosis stage was developed through visits, followed tours and semi-structured questionnaires. After the bibliographical review and recognition of the empirical object, there was the design stage with emphasis on community participation through workshops. The partial result of the first year was the prototyping of 144 real-scale plates and one of the proposed tactile maps, the pagination of tactile floors, as well as the organization
\end{abstract}

NÓBREGA, A. P. O.; VIEIRA, M. C. S.; DINIZ, M. A. Projeto participativo de sinalização acessível para a reitoria da UFPB. In: SIMPÓSIO BRASILEIRO DE QUALIDADE DO PROJETO NO AMBIENTE CONSTRUÍDO, 6., 2019, Uberlândia. Anais... Uberlândia: PPGAU/FAUeD/UFU, 2019. p 771-779. DOI https://doi.org/10.14393/sbqp19071. 
guidelines of the systems for the deepening and continuity of the project that would support the right of to come and go from the community equally.

Keywords: UFPB's Rectory, Accessible Signaling, Prototyping, Participative Project.

\section{INTRODUÇÃO}

Espera-se que as pessoas possam se localizar e locomover de modo autônomo, tanto no contexto urbano quanto arquitetônico, visando chegar em segurança ao objetivo que destinam. Entretanto, diversas edificações, principalmente as de uso público, não são dotadas de acessibilidade espacial plena. Segundo a lei número 13.146 (BRASIL, 2015) existe um conjunto de barreiras físicas e atitudinais que interferem diretamente na vivência das cidades e da arquitetura para as pessoas com alguma deficiência, seja física ou mental. Num cenário onde a própria acessibilidade não recebe a devida ênfase necessária como variável intrínseca da produção projetual, torna-se comum encontrar a sinalização sendo interpretada como um mecanismo auxiliar e supérfluo, não essencial.

Assim, os sistemas de sinalização comummente encontrados usualmente destacam-se arbitrariamente como a identificação genérica de ambientes. Também utilizando materiais efêmeros, que não desempenham a função com excelência, dada a sua fragilidade. Quando há maior refinamento são encontrados conjuntos básicos de elementos para sinalização emergencial, como indicações de saídas e escadas. Todavia, segundo o decreto de lei número 5.296 (BRASIL, 2004) as edificações de ensino, em todos seus níveis sendo particulares ou públicas, devem oferecer condições de acesso e uso igualitário em todos os seus ambientes para pessoas com ou sem deficiências.

Boa parte dos campi de universidades federais são históricos e suas edificações foram construídas muito antes da valorização da acessibilidade como uma variável de produção projetual. Através das diretrizes de intervenção em edificações preexistentes apresentadas na NBR 9050 (ABNT, 2015) é fomentado esse processo de adaptação para regularizar as obras às demandas de sua comunidade.

O caso da reitoria da Universidade Federal da Paraíba não é diferente. Sua evolução histórica, no que diz respeito às modificações arquitetônicas, sempre foi pautada na funcionalidade. Assim, em sua atualidade, é uma edificação com programa de necessidades bastante complexo e articulado, detendo diferentes perfis de organização espacial, consequência das diferentes épocas dos processos de modificação espacial.

Esta pesquisa se mostra pioneira no campus I da universidade, ao buscar entender o desempenho desta edificação. Dada seu caráter emblemático para o funcionamento da instituição e sendo por isso o alvo do primeiro ano da atividade de extensão. Através do estudo em campo foram diagnosticas as principais problemáticas em respeito à sinalização da edificação. Servindo como parar da proposição efetiva de soluções que permitam uma melhor vivência e orientação para toda a comunidade, guiando-se por diretrizes do desenho universal e Wayfinding (SIMÕES, 2017).

Como objetivo primário buscava entender e diagnosticar as demandas principais, em respeito à orientabilidade, da comunidade acadêmica da universidade federal da Paraíba. Deste modo, com base nos dados do CENSO 
(IBGE, 2010) foram traçados os principais perfis da população paraibana, em sua totalidade, para possibilitar uma divisão lógica dos grupos de análise a fim de envolver indivíduos com e sem deficiência referenciando as proporções da comunidade.

Para que o estudo pudesse aprofundar seu diagnóstico e desenvolvê-lo com maior eficácia foi necessário um recorte espacial. A análise restringiu-se ao estudo do primeiro pavimento por este sediar o Comitê de Inclusão e Acessibilidade. Órgão responsável por diversos projetos e ações para integração da comunidade com deficiência presente na universidade, tornando-se assim um espaço simbólico para o estudo atual.

Através do diagnóstico foram determinadas as fraquezas na edificação em sua unidade - graças a sua similaridade de função entre pavimentos embasando as diretrizes projetuais para a futura execução e implantação dos sistemas integrados de sinalização acessível. Portanto, esta pesquisa justifica-se por somar aos estudos que envolvam a sinalização em seus diversos cenários possíveis e encontrar sistemas que unam diversas variáveis, como elementos visuais, auditivos e táteis e que busquem integrar os diversos grupos de usuários.

\section{FUNDAMENTAÇÃO TEÓRICO-METODOLÓGICA}

O que é um espaço acessível? Para muitos é apenas um espaço possível de trânsito em que não exista quaisquer barreiras físicas. Entretanto, este é um juízo errôneo. Segundo Dischinger, Ely e Piardi (2012) a acessibilidade espacial vai além de poder chegar ao ambiente desejado. É imprescindível o local possibilite ao usuário entender as funcionalidades e relações espaciais, como também, poder participar destas de modo seguro, confortável e independente (BRASIL, 2015). No objeto empírico do estudo - primeiro pavimento da reitoria da Universidade Federal da Paraíba, campus I, João Pessoa - foi entendido, através das visitas de reconhecimento, que os elementos de sinalização são ineficientes e/ou inexistentes.

As informações são contrastantes e de difícil compreensão, principalmente ao buscar apoio na recepção presente no hall de chegada ao pavimento. Graças à complexidade e relações entre pavimentos, as salas são dificilmente encontradas. Além disso, a própria configuração espacial do pavimento já é difícil, consequência dos corredores confusos e com muitas mudanças de fluxo (Figura 1).

As poucas placas presentes acabam por não se destacarem e são, em sua maioria, feitas em papel ofício, tornando-se elementos frágeis e facilmente danificáveis. São, em sua totalidade, fixadas diretamente nas portas, porém não há um padrão/linguagem único, como também, não possuem padrão de fixação, tornando-se muitas vezes inacessivveis para leitura (ABNT,2015).

Como organização da pesquisa, no que diz respeito às suas etapas, pode-se dividi-la em dois principais momentos. Inicialmente pela revisão bibliográfica e documental para reconhecimento da qualidade do objeto de estudo teórico - acessibilidade e conceitos que integrassem ao interesse da pesquisa, como desenho universal, ergonomia, design gráfico, etc. Há também o reconhecimento dos dados gráficos da edificação, através de revisão de seus documentos - plantas baixas, cortes e modelagens tridimensionais. Após a 
etapa de reconhecimento foi entendida a necessidade do recorte para apenas um pavimento, bem como, possibilitou traçar os percursos de análise para as futuras rotas acessíveis de sinalização. Como também, para a estruturação das etapas vindouras de análise prática e da qualidade construída da edificação.

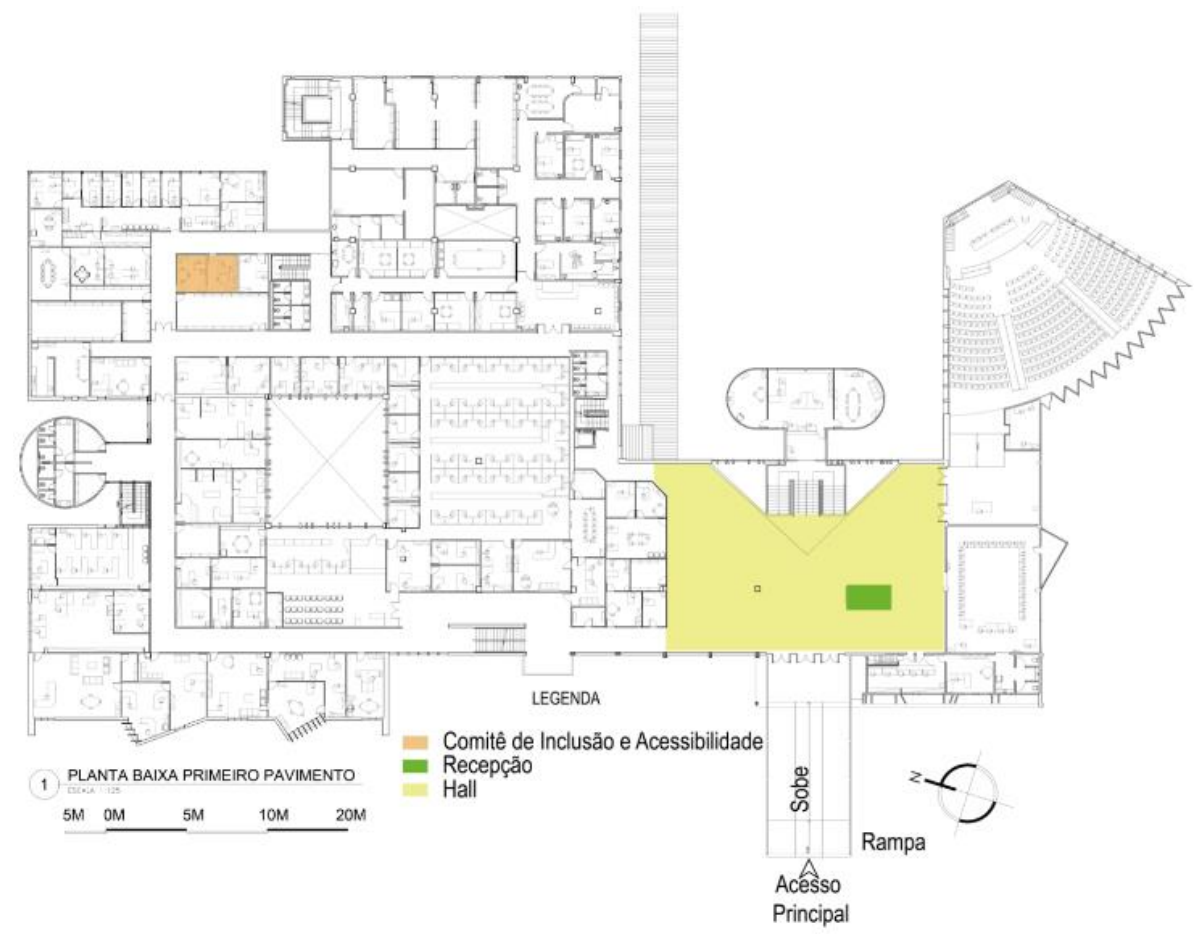

Figura 1 - Planta baixa do primeiro pavimento com destaque para Hall, Recepção e Comitê de Inclusão e Acessibilidade -

Fonte: Autores (2019)

Graças ao caráter participativo da ação de extensão, visando compreender de fato as demandas do público e buscando gerar o diagnóstico através da perspectiva da comunidade acadêmica, a metodologia de passeios acompanhados surgiu como mecanismo da etapa prática (DISCHINGER; BINS ELY; PIARDI; 2012). Este processo foi desenvolvido com trinta e dois voluntários - distribuídos entre deficientes visuais, auditivos, físico-motores, mobilidade reduzida e sem deficiência. Consistia em percorrer o pavimento em busca do Comitê de Inclusão e acessibilidade, onde o voluntário teria total autonomia para orientar-se segundo seus critérios, podendo ou não pedir informações e guiar-se pelas placas.

Ao encontrar o Comitê de Inclusão e Acessibilidade o voluntário seria direcionado ao hall principal por outro percurso e então através de um questionário semiestruturado - com perguntas fechadas - evidenciaria suas opiniões e dificuldades sobre a orientação e sinalização. Após a etapa de diagnóstico chegou-se ao último momento prático onde foram construídos protótipos digitais em softwares diversos e ferramentas do pacote Adobe. Estas plataformas digitais foram utilizadas para a criação e estudo do design dos elementos de sinalização. Para dar ênfase ao caráter participativo as propostas foram apresentadas através de Workshops à comunidade, possibilitando o refinamento de sua qualidade estética e funcional. Por fim, houve a prototipagem física, em escala real das placas (Figura 2). Esta foi 
utilizada como última ferramenta para uma percepção rápida dos ouvintes com relação à aplicabilidade dos produtos.

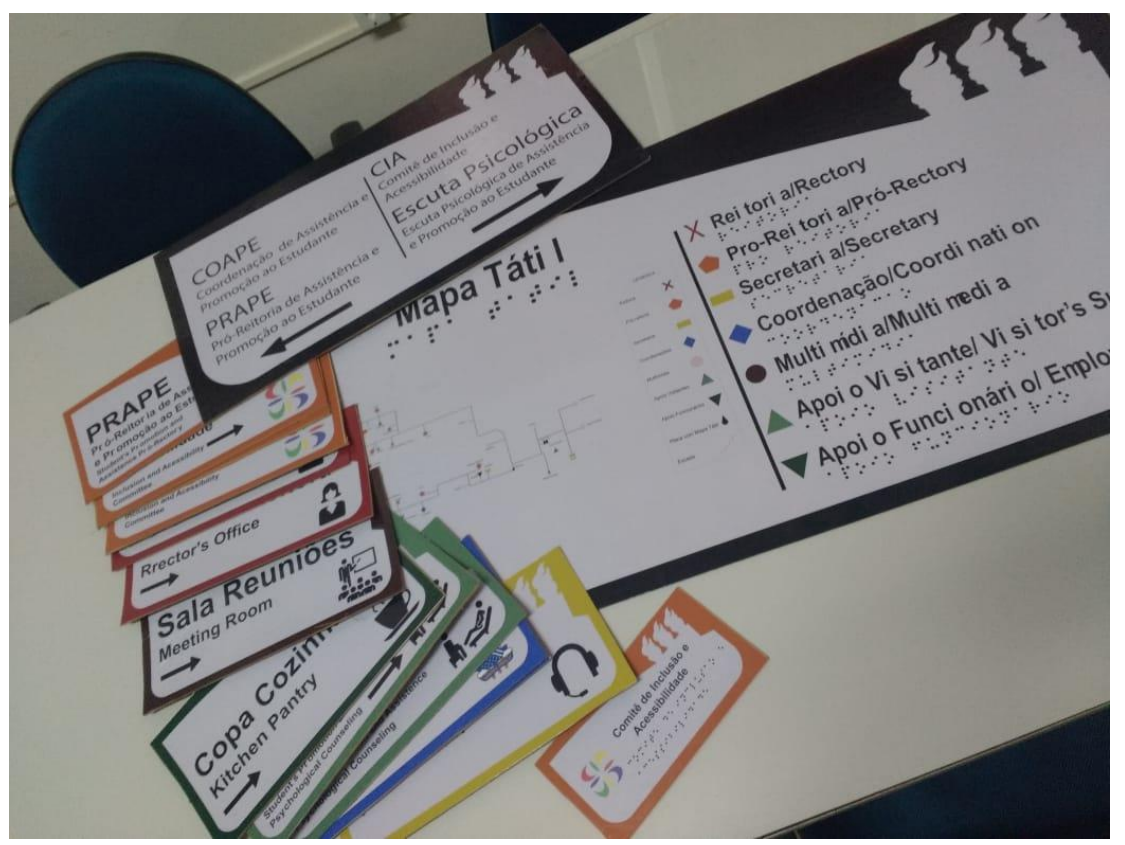

Figura 2 - Protótipos das placas em escala real para apresentação da proposta Fonte: Autores (2018)

As participações ativas da comunidade continuaram até o fim da etapa projetual, uma vez que, segundo Veloso e Elali (2014) elas são de suma importância seja para projetos arquitetônicos ou urbanísticos. Com os futuros usuários participando efetivamente do processo de criação as principais dúvidas sobre a eficácia do produto inicial puderam ser sanadas. Estas eram questões como a utilização de cores como forma de atração e distinção dos usos, setorização de fácil entendimento, posicionamento de placas ao longo da edificação entre outras. Dessa forma o produto foi sendo melhorando continuamente, servindo como base para sua continuação com maior eficácia e qualidade formal/funcional.

\section{RESULTADOS E DISCUSSÃO}

Referente ao diagnóstico foram destacadas um conjunto de instabilidades e fraquezas presentes na reitoria, com foco em seu primeiro pavimento:

I. Má qualidade da informação geral;

II. Dificuldade de orientação pelas orientações orais fornecidas por usuários, funcionários e visitantes;

III. Inexistência de informação tátil, auditiva e tecnologias assistivas;

IV. Sinalização parca, ineficiente, em má qualidade e utilizando-se de materiais frágeis;

V. Dificuldade da legibilidade espacial decorrente da complexidade de sua planta baixa;

VI. Falta de macrozoneamento na edificação com base em suas funções. 
Em decorrência dos pontos levantados e das críticas por parte dos voluntários, já incorporadas nos pontos acima, as diretrizes projetuais foram traçadas para criar sistemas de sinalização integrados que pudessem sanar estas defasagens e proporcionar autonomia. Nesse sentido, buscando integrar os grupos das deficiências previamente abordadas os sistemas iriam se munir de informações táteis, visuais e auditivas, como também de ferramentas assistivas. Algumas das propostas não puderam ser aprofundadas no primeiro ano da iniciativa de extensão, sendo estruturadas em diretrizes e organizadas para o segundo ano que serviria para o projeto executivo abrangente à todas as ferramentas. Como macro resultado foram gerados sistemas:

I. Visual: composto de placas em diferentes formatos, totens informativos em pontos de maior fluxo e divisão de setores com base em cores para criação de identidade visual e guias direcionais pelo piso.

II. Tátil: Mapas táteis dispostos em pontos estratégicos do pavimento e também nos totens informativos; paginação de pisos táteis e informação em Braille.

III. Auditiva/Ferramentas assistivas: Proposta da criação de uma plataforma audiovisual com acesso por QrCode que através de sensores dispostos por todo o pavimento viria a indicar trajetos para as salas escolhidas pelo usuário assim que ingressasse na plataforma digital.

A principal característica destes sistemas é a possiblidade de se integrarem ou não. Eles desempenham a sinalização de forma eficiente em aplicação autônoma, porém ao serem integrados fornecem uma sistematização maior da informação e possibilidade de orientar mais pessoas. Além disso, pela sua construção baseada em diretrizes gerais, a adaptabilidade do projeto é elevada, podendo ser implantada em outras edificações sofrendo poucas modificações. O segundo macro resultado se deu na criação de setores, estes visando facilitar a fragmentação da informação e possibilitar a criação da identidade visual para cada um dos grandes grupos, resultando em:

I. Reitorias: salas diretamente relacionadas ao gabinete do(a) Reitor(a), sendo entendidas como mais restritas e de maior grau de influência. Sua identidade deu-se pela cor vermelha - utilizada nas placas, nas guias com cor e no mapa tátil sob o símbolo X preenchido.

II. Pró-Reitorias: salas das pró-reitorias propriamente ditas, seus anexos e todas as outras repartições que são diretamente coordenadas por elas. Sua identidade deu-se na cor laranja e como símbolo para os mapas táteis detinha um pentágono preenchido.

III. Secretarias: Ambientes de apoio e de ouvidoria gerais para a instituição, sendo espaços com média restrição. Sua identidade deu-se na cor amarela e como símbolo para mapas utilizou-se da forma retangular.

IV. Coordenações: Salas responsáveis por eventos mais abertos à comunidade e com restrição abaixo das secretarias. Seria identificada através da cor azul e como símbolo, um losango.

V. Multimídia: Salas de reunião abertas ao público, auditórios, bibliotecas e arquivos. Sua identidade é a cor marrom como símbolo, o círculo. 
VI. Apoio Funcionários: Salas de descanso, almoxarifados, copas e ambientes destinados aos usuários. Como cor teria o verde bandeira e como símbolo um triângulo invertido.

VII. Apoio Visitantes: Recepções, halls, jardins, banheiros e todos os ambientes de apoio do gênero. Como cor teria o verde folha e como simbologia um triangulo equilátero.

No sistema de sinalização visual propunha-se, segundo princípios de autonomia do Wayfinding (ARTHUR; PASSINI, 1992; SIMÕES, 2017) a utilização da cor como elemento de separação dos setores, bem como de orientação até estes. Nesse cenário, no hall principal do pavimento seria implantada um painel - seguindo o padrão estético das outras placas - com a definição dos setores, suas cores e seus símbolos (Figura 3). A partir da placa as sete faixas coloridas iriam descer até o chão e se organizariam pelo piso para todas as salas presentes, respeitando seus setores e identidade visual, sendo diretamente integrados à paginação de pisos táteis.

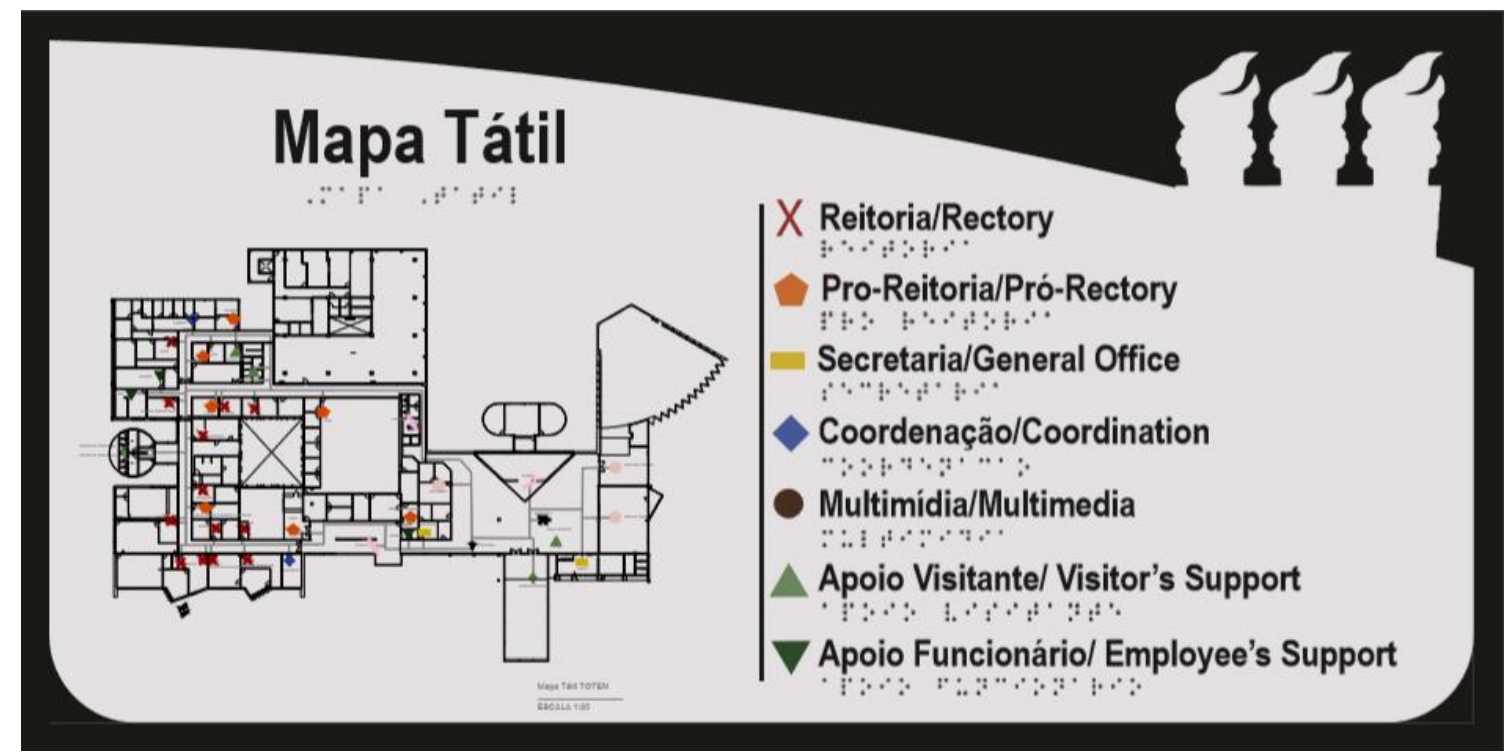

Figura 3 - Protótipo da placa inicial com divisão dos setores e mapa tátil geral do pavimento com planta baixa em segundo plano Fonte: Autores (2018)

Sobre a tecnologia assistiva que seria integrada ao sistema de informação auditiva as expectativas mantiveram-se apenas em proposições e diretrizes gerais. Seu funcionamento seria articulado com base na transição de um sistema de Posicionamento Global por Satélite (GPS) porém não em escala urbana, mas sim arquitetônica. O funcionamento esperado seria na mesma sistematização, guiando o usuário através de informações precisas como "vire à direita/esquerda", "siga em frente" e "você chegou ao seu destino".

O acesso a esta plataforma se daria pela leitura de um QrCode implantado nos totens informativos. Após entrar o usuário indicaria seu objetivo na edificação, para a partir disso ser direcionado através de informação visual e auditiva simultâneas. Deste modo, qualquer usuário poderia utilizar-se da ferramenta para orientar-se eficientemente na edificação.

Para validação destas propostas os workshops serviram como principal ferramenta, mantendo continuamente a participação da comunidade desde 
a etapa de diagnóstico até o final da propositiva. Nas três situações foram expostas um conjunto de variações para a mesma solução, onde o diálogo serviu para refinamento do número - partindo de seis soluções diferentes para três durante o primeiro workshop e de três para uma na segunda apresentação. A terceira exposição pública serviu para apresentar a proposta final à comunidade acadêmica como um todo, ocorrendo durante o evento promovido pela instituição para acompanhamento dos projetos de extensão (XIX ENEX).

Por fim, tem-se o registro total das diretrizes projetuais que pautaram a evolução desta pesquisa, sendo estas fundamentações para as etapas seguintes e/ou aplicação entre outras edificações e instituições.

I. Sinalizar com base na equidade e desenho universal.

II. Propor, seguindo o princípio de adaptabilidade, soluções que possam ser facilmente modificadas e utilizadas em outras situações

III. Sinalizar com baixa hostilidade visual, criando mecanismos que auxiliem na percepção espacial sem incomodarem a visão, utilizando-se assim de formas orgânicas.

IV. Valorizar a instituição responsável, possibilitando a simbologia de seu brasão e de identidade da obra.

v. Utilizar-se de linguagem simples e facilitada para veiculação da informação e do produto.

\section{CONSIDERAÇÕES FINAIS}

A abordagem prática e teórica deste estudo evidencia-se como uma ferramenta de extrema importância para a formação acadêmica. Visto que, trata-se de um projeto desenvolvido na graduação em arquitetura e urbanismo que possibilitou a vivência tanto no âmbito de pesquisa quanto de produção projetual. Destaca-se também a variabilidade de grupos diretamente envolvidos na pesquisa, desde discentes e docentes a servidores e visitantes. Essa diversidade possibilitou o entendimento de diferentes perspectivas não apenas no que diz respeito à deficiência, mas também ao grau de reconhecimento do objeto de estudo.

Outro ponto importante é a influência da metodologia participativa, evidenciando-se como ferramenta que gera um produto muito mais íntimo ao usuário e que mais facilmente resolverá suas problemáticas, visto que, ele fora entendido como principal ator, recebendo o máximo destaque, não o projeto em si. Assim, ao traçar diretrizes ao lado da comunidade torna-se mais fácil uma boa qualidade projetual, que seja realmente eficaz no que se propõe e que vá ter o uso por parte da população.

A participação efetiva da comunidade até mesmo em detalhes como o dimensionamento de fontes foi muito importante para a produção do projeto, deixando-o estruturado para sua continuação no ano de 2019. Em relação ao processo em sua totalidade, algumas dificuldades se estruturam pelo caminho. Uma delas seria o fato da falta de apoio financeiro para a pesquisa, visto que, todo o processo de prototipagem e impressão em escala real das placas foi custeada pela autoria da pesquisa. 
Além disso, a falta de domínio de algumas das ferramentas de prototipagem também atrasaram um pouco o desenvolver do projeto. Há também o fato da necessidade de apoio de outras áreas de conhecimento para a criação dos sistemas de tecnologias assistivas.

Enfatizamos a contribuição para instituição de um projeto de sinalização que integre mais variáveis em sua produção, levando benefícios aos usuários. Destaca-se também a materialidade gerada dos elementos de sinalização, possibilitando testes futuros após uma implantação simulada do produto da pesquisa.

Conclui-se que foi possível desenvolver para o edifício da reitoria da UFPB um projeto de sinalização em edificação com programa de necessidades complexo. Além disso, por munir-se de diferentes formas de estruturação de ideias e produtos o projeto torna-se um plano piloto de sinalização possível de replicação nas demais edificações com dificuldade de legibilidade.

\section{REFERÊNCIAS}

ARTHUR, P.; PASSINI, R. Wayfinding: People, Signs, and Architecture, Ontario: McGraw-Hill Ryerson Ltd. Original reissued as a collector's edition in 2002 by Focus Strategic Communications, Inc. 1992.

ASSOCIAÇÃO BRASILEIRA DE NORMAS TÉCNICAS (ABNT). NBR 9050:

Acessibilidade a edificações, mobiliário, espaços e equipamentos urbanos. Rio de Janeiro, 2015.

BRASIL. Decreto-lei $n^{\circ} .5 .296,2$ de dezembro de 2004. Regulamenta as Leis $n^{\circ}$ 10.048, de 8 de novembro de 2000, que dá prioridade de atendimento às pessoas que especifica, e $\mathrm{n}^{\circ} 10.098$, de 19 de dezembro de 2000, que estabelece normas gerais e critérios básicos para a promoção da acessibilidade das pessoas com deficiência ou com mobilidade reduzida, e dá outras providências. Brasília, 2004.

BRASIL. Lei n $^{\circ}$ 13.146, de 6 de julho de 2015. Institui a Lei Brasileira de Inclusão da Pessoa com Deficiência (Estatuto da Pessoa com Deficiência). Brasília, 2015.

DISCHINGER, M.; BINS ELY, V.; PIARDI, S. Promovendo acessibilidade espacial

nos edifícios públicos: programa de acessibilidade às pessoas com deficiência ou mobilidade reduzida nas edificações de uso público. Florianópolis: Ministério Público do Estado de Santa Catarina, 2012.

INSTITUTO BRASILEIRO DE GEOGRAFIA ESTATíSTICA (IBGE). Censo 2010. Disponível em: <https://censo2010.ibge.gov.br/noticias-

censo? $i d=3 \&$ idnoticia=2170\&view=noticia>. Acesso em: 05 jun. 2019.

SIMÕES, P. "Se Deus te assinalou algum defeito te encontrou" o design e contributos para a sinalética urbana. In: Congresso Internacional Cidades Criativas. 5, 2017. Cidade do Porto. Anais... Cidade do Porto, 2017.

VELOSO, M.; ELALI, G. A. Projeto como construção coletiva: da participação à colaboração -os desafios do ensino. In: Encontro da Associação Nacional de Pesquisa e Pós-graduação em Arquitetura e Urbanismo. Arquitetura, cidade e projeto: uma construção coletiva. 3, 2014, São Paulo. Anais: ANPARQ. São Paulo, 2014. 